\title{
The Burden and Long-term Respiratory Morbidity Associated with Respiratory Syncytial Virus Infection in Early Childhood
}

\author{
Brigitte Fauroux - Eric A. F. Simões · Paul A. Checchia - Bosco Paes • \\ Josep Figueras-Aloy · Paolo Manzoni · Louis Bont • \\ Xavier Carbonell-Estrany
}

Received: February 1, 2017 / Published online: March 29, 2017

(C) The Author(s) 2017. This article is an open access publication

\section{ABSTRACT}

Introduction: The REGAL (RSV Evidence-a Geographical Archive of the Literature) series provide a comprehensive review of the published evidence in the field of respiratory syncytial virus (RSV) in Western countries over the last 20 years. The objective of this fifth publication was to determine the long-term respiratory morbidity associated with RSV lower

Enhanced content To view enhanced content for this article go to http://www.medengine.com/Redeem/ F6E4F06044E2A44B.

Electronic supplementary material The online version of this article (doi:10.1007/s40121-017-0151-4) contains supplementary material, which is available to authorized users.

B. Fauroux

Necker University Hospital and Paris 5 University, Paris, France

\section{E. A. F. Simões}

University of Colorado School of Medicine, and Center for Global Health, Colorado School of Public Health, Aurora, CO, USA

\section{P. A. Checchia}

Baylor College of Medicine, Texas Children's

Hospital Houston, Houston, TX, USA

B. Paes

Department of Paediatrics (Neonatal Division), McMaster University, Hamilton, Canada respiratory tract infection (RSV LRTI) in early life.

Methods: A systematic review was undertaken for articles published between January 1, 1995 and December 31, 2015. This was supplemented by inclusion of papers published whilst drafting the manuscript. Studies reporting data on the incidence and long-term wheezing and asthma following RSV LRTI in early life were included. Study quality and strength of evidence (SOE) were graded using recognized criteria.

Results: A total of 2337 studies were identified of which 74 were included. Prospective, epidemiologic studies consistently demonstrated that RSV LRTI is a significant risk factor for on-going respiratory morbidity characterized by transient early wheezing and recurrent wheezing and asthma within the first decade of life and possibly into adolescence and adulthood

\footnotetext{
J. Figueras-Aloy

Hospital Clínic, Catedràtic de Pediatria, Universitat de Barcelona, Barcelona, Spain

P. Manzoni

Sant'Anna Hospital, Turin, Italy

L. Bont

University Medical Center Utrecht, Utrecht, The Netherlands

X. Carbonell-Estrany $(\square)$

Hospital Clinic, Institut d'Investigacions

Biomediques August Pi Suñer (IDIBAPS), Barcelona, Spain

e-mail: carbonell@comb.cat
} 
(high SOE). RSV LRTI was also associated with impaired lung function in these children (high SOE). Respiratory morbidity has been shown to result in reduced quality of life and increased healthcare resource use (moderate SOE). The mechanisms through which RSV contributes to wheezing/asthma development are not fully understood, but appear to relate to the viral injury, preexisting abnormal lung function and/ or other factors that predispose to wheezing/ asthma, including genetic susceptibility, altered immunology, eosinophilia, and associated risk factors such as exposure to environmental tobacco smoke (high SOE).

Conclusion: There is growing evidence that RSV LRTI in early childhood is associated with long-term wheezing and asthma and impaired lung function. Future research should aim to fully elucidate the pathophysiological mechanisms through which RSV causes recurrent wheezing/asthma.

Keywords: Asthma; Bronchial hyperreactivity; Bronchiolitis; Lower respiratory tract infection; Lung function; Recurrent wheezing; Respiratory morbidity; Sensitization; Wheezing

\section{INTRODUCTION}

Respiratory syncytial virus (RSV) is a leading cause of lower respiratory tract infection (LRTI) in children worldwide, with severe infection resulting in hospitalization and considerable morbidity $[1,2]$. Previous infection with RSV does not convey persistent immunity and reinfection is common, though the severity of infection tends to decrease with increasing age [3]. There are well-characterized risk factors for RSV hospitalization (RSVH) including prematurity, chronic lung disease (CLD) and congenital heart disease (CHD) [4-8]; however, the majority of children hospitalized for RSV LRTI are previously healthy and have no risk factors for severe disease $[7,9]$. In addition to the acute burden of RSV, epidemiological data suggest that RSV infection in the first 3 years of life is associated with long-term respiratory morbidity, such as recurrent wheezing and asthma, decreased lung function, and possibly allergic sensitization [10-12]. Such respiratory morbidity may persist into early adulthood $[12,13]$. These long-term effects may reduce quality of life (QoL) and increase healthcare resource utilization $[14,15]$.

The etiological link between RSV infection and the development of asthma has long been debated. It is unclear whether severe RSV LRTI causes wheezing, or if genetic predisposition or other environmental risk factors increase the propensity for an exaggerated response to RSV [16]. It has been proposed that both of these pathways may be relevant, and that there may be differential effects based on the child's atopic predisposition and the specific viral genotype [2]. It remains unclear, however, which children hospitalized for severe RSV infection will develop recurrent wheezing and/or asthma later in life. Predicting which children are at risk for long-term respiratory problems could identify specific populations who would benefit from early targeted interventions.

The primary objective of REGAL (RSV Evidence-a Geographical Archive of the Literature) was to carry out a series of systematic reviews and then to assess, quantify, summarize and grade the evidence base for severe RSV infection in Western societies over the past 20 years [17-20]. REGAL was undertaken by an expert panel, comprising neonatologists, pediatricians, pediatric infectious disease specialists, pediatric cardiologists and pediatric pulmonologists from the United States, Canada and Europe. This paper, which represents the fifth in a series of seven publications covering a range of topics on RSV disease, identifies and describes the incidence, risk factors and long-term effects of respiratory morbidity and allergic sensitization after RSV LRTI in early life.

\section{METHODS}

The primary objective of REGAL was to address seven specific research questions relating to RSV covering: epidemiology [17]; premature infants [18]; CLD [19]; CHD [20]; special populations (e.g. Down syndrome); prevention and future management; and long-term respiratory morbidity, the focus of this paper. The systematic 
reviews undertaken to answer each research question all used the same broad methodology, which has been described elsewhere [17]. The full protocol and generic search terms for the systematic reviews are available as part of the online supplement. To ensure that the literature search was manageable, only studies conducted in Western countries, which we defined as the United States, Canada, and Europe (including Turkey and the Russian Federation), were included.

In this systematic literature review, we sought to answer the following question: What is the nature, incidence and impact on longterm respiratory morbidity after RSV LTRI in early life in Western countries, specifically early and late wheeze? The search for this systematic review included studies published between January 1, 1995 and December 31, 2015 indexed in PubMed, EMBASE, the Cochrane Library, and clinicaltrials.gov. The target population was children who were hospitalized for RSV LRTI in early childhood (first 2-3 years of life) and subsequently developed recurrent wheezing/asthma in later life. RSVH was defined as hospital admission for lower respiratory tract symptoms (deep or wet chest cough, wheezing, hoarseness, stridor, shortness of breath) and either a positive enzyme immunoassay or a positive direct immunofluorescence assay for RSV infection of epithelial cells in nasopharyngeal secretions, a positive polymerase chain reaction test or a positive viral culture for RSV.

The following general terms and limits were used in the literature search: "RSV" OR "respiratory syncytial virus" AND "hospital" OR "admission" OR "admitted" AND "respiratory morbidity" OR "respiratory sequelae" OR "complication" OR "manifestation" OR "consequence" OR "long-term" OR "long term" OR "outcome" OR "wheezing" OR "wheeze" OR "asthma AND "limits: human, child (birth-18 years)". "Bronchiolitis" and "pneumonia" were captured as part of the Medical Subject Headings (MeSH) terms. We recognize that, while some relevant articles might have been missed by the searches, the combined Boolean operators "AND" and "OR" of the key text words and index terms should have precisely captured the vast majority of relevant citations which were pertinent for this evidence-based review. The search results were supplemented by a review of the bibliographies of key articles for additional studies and inclusion of relevant abstracts presented at key meetings. Other significant studies of the target population, published during the drafting of the manuscript, were also included in the review, as identified by the authors.

\section{Definition of Asthma and Recurrent Wheezing}

A variety of definitions of wheezing and asthma have been used in studies of RSV. A formal diagnosis of asthma is outlined in the International Statistical Classification of Diseases and Related Health Problems (ICD) 10 code of J45 or an International Classification of Primary Care (ICPC) code of R96 [21, 22]. The ICPC also provides a specific code for wheezing: R03. For completeness, we have included all relevant studies in the review and provided the definitions used within the summary tables. For future studies, we would recommend that 'current asthma' be defined as a history of asthma diagnosed by a physician, plus asthma symptoms or medication (beta-mimetics or inhaled corticosteroids) use in the last 12 months [23]. For this review, recurrent wheezing was defined as 3 or more wheezing episodes within 12 months, reported by either a physician (preferably) or a patient [14].

\section{Outcomes of Interest}

The outcomes of interest for this review included:

(i) asthma, recurrent wheezing and allergic sensitization rates after RSV LRTI in early life,

(ii) lung function after RSV LRTI in early life,

(iii) the relationship between RSV LRTI and subsequent development of clinical allergy or allergic sensitization, and

(iv) factors associated with the development of recurrent wheezing/asthma after RSV LRTI in early life. 


\section{Evaluation of Data}

Included publications were graded according to the Oxford Centre for Evidence-Based Medicine Levels of Evidence [24, 25] (Supplementary Material 1-REGAL Protocol). For each study, we conducted a risk of bias assessment using the RTI Item Bank (score of $1=$ very high risk of bias; score of $12=$ very low risk of bias) for observational studies [26]. No quantitative data synthesis was conducted due to heterogeneity between studies in terms of design, patient populations, RSV testing, recording and availability of outcomes, and differences in clinical practice between countries and over time.

\section{Compliance with Ethics Guidelines}

The analysis in this article is based on previously published studies and does not involve any new studies of human subjects performed by any of the authors.

\section{RESULTS}

\section{Articles Selected}

From a total of 2337 publications, 74 studies were included in the final review: 58 identified from the database searches and a further 16 from reference lists/other sources (Fig. 1). Data extraction tables for all 74 studies, including evidence grades and risk of bias assessments can be found in the online supplement.

\section{RSV LRTI in Early Life and the Risk of Developing Recurrent Wheezing/ Asthma}

Evidence from an increasing number of studies suggests a strong association between severe RSV LRTI in children aged $<3$ years and the subsequent development of recurrent wheezing/asthma in later life [10-14, 23, 27-44]. Due to differences in study design and methodology,

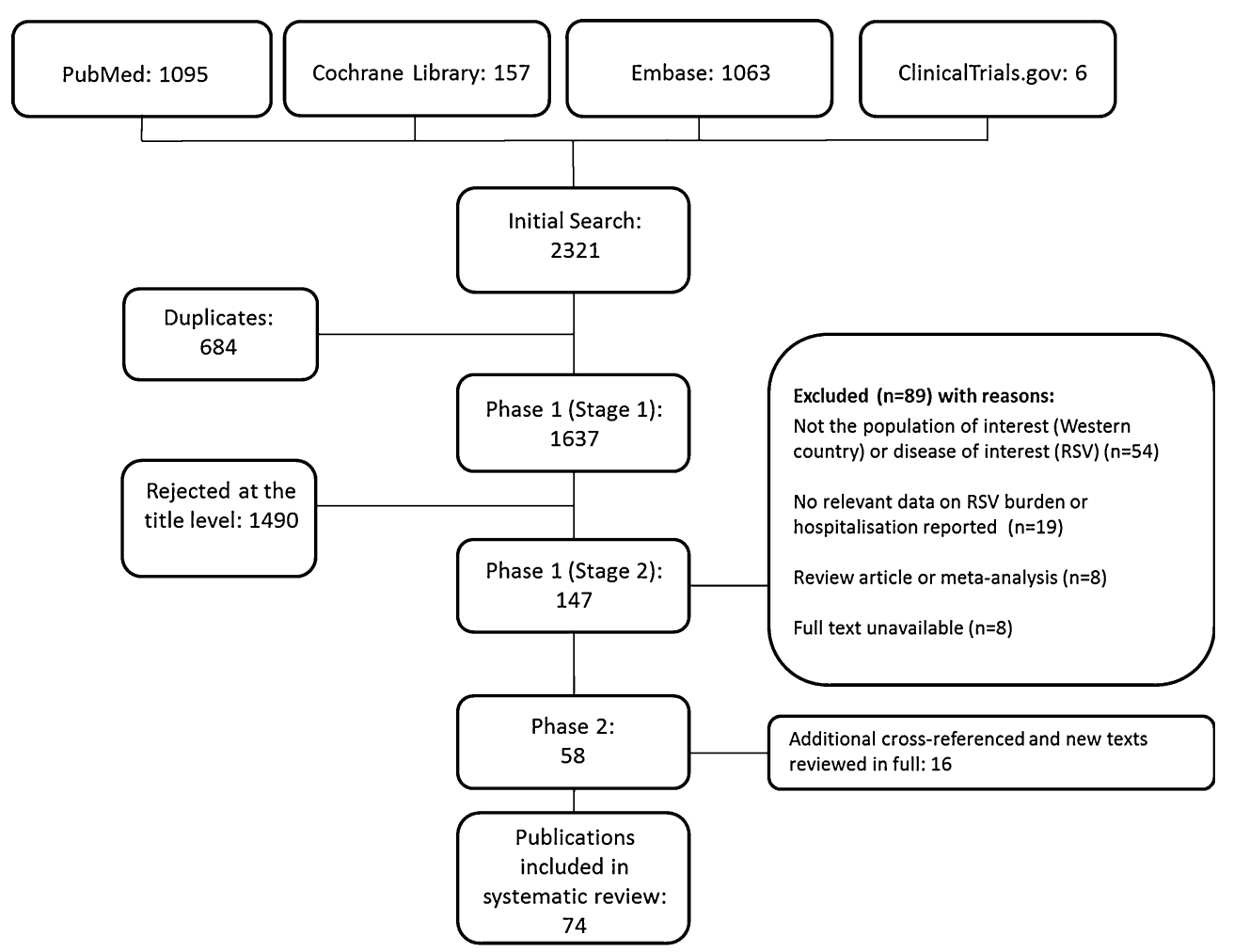

Fig. 1 PRISMA flow diagram: Incidence and impact of long-term respiratory morbidity associated with RSV LRTI in early life 
definitions of wheezing/asthma used (including whether asthma is current/active), patient populations and length of follow-up, the reported rates of recurrent wheezing and asthma vary considerably across studies (Table 1). Following RSV LRTI in early childhood ( $\leq 3$ years old), recurrent wheezing rates of $4-47 \%$ and asthma rates of $8-76 \%$ have been reported in studies with up to 25 years follow-up (average follow-up 6-8 years) $[14,28,33,42]$.

Several studies have indicated that, for many children, RSV-associated wheezing might be a transient event, diminishing over time, and may be even disappearing to background levels in early adolescence $[10,11,28,30,31,45]$. In the Tucson Children's Respiratory Study, carried out in the United States, an increased risk of subsequent wheeze in children aged $<3$ years with RSV LRTI (most of whom were not hospitalized) was observed until the age of 11 years, but, by the time these children were 13 years of age, the association between wheeze and RSV LRTI was no longer significant [30]. Sigurs et al. followed a cohort of 47 Swedish infants aged $<12$ months hospitalized for severe RSV infections and 93 matched controls at ages 3, 7, 13 and 18 years [10, 11, 28, 29]. Up to age 7 , recurrent wheezing was significantly more frequent in the RSVH group compared with control subjects $(13.0 \%$ vs. $0 \%$, respectively; $P<0.001)$ [10], though the difference, albeit still higher in the RSVH group, was not significant by age 13 (30\% vs. $16.3 \% ; P=0.093)$ [11]. At 18 years, results specifically for recurrent wheezing were not presented, but when recurrent wheezing was combined with asthma, rates were significantly higher for those with a history of RSVH than with controls (39\% vs. 9\%, respectively; $P=0.001$ ) [29]. Another long-term study reported RSV-associated wheezing to persist at $>25$ years of age [35\% vs. $16.3 \%$ of controls; odds ratio (OR) 2.79, 95\% confidence interval (95\% CI) 1.15-6.75] [13]. Hence, whilst there is evidence that RSV-associated wheezing tends to diminish with time, it can persist into adulthood in some patients.

A number of prospective studies have demonstrated that RSV LRTI in childhood is an important risk factor for asthma in early adulthood [10, 12, 13, 29, 32]. In the study by Sigurs et al. [10], multivariate analysis at the 7-year follow-up showed that RSV bronchiolitis had the highest independent risk ratio for asthma (OR, 12.7; 95\% CI, 3.4-47.1). This was reconfirmed in the 18-year analysis, where RSVH was an independent risk factor for current asthma/recurrent wheeze (OR, 6.2; 95\% CI, 2.0-19.2; $P<0.001)$ and current asthma alone (OR, 7.2; 95\% CI, 2.1-23.9; $P<0.001$ ) [29]. Current asthma was reported in $33 \%$ of RSVH subjects and $7 \%$ of controls at up to 18 years of age $(P<0.001)$ [29]. The RSV Bronchiolitis in Early Life study (REBEL) also supports the link between RSV LRTI in childhood and physician-diagnosed asthma by school age [40]. In this prospective cohort study, nearly half (48\%) of the children who developed severe RSV LRTI in the first year of life were diagnosed with childhood asthma by 7 years of age. The authors identified that greater levels of nasal epithelial expression of the chemokine CCL5 at the time of bronchiolitis were strongly predictive of physician-diagnosed asthma by the 7th birthday [40]. Other studies have demonstrated that RSVH at $<2$ years of age is a significant risk factor for adulthood asthma at 18-20 years [12] and $>25$ years [13]. Based on the findings of a retrospective study analyzing cohort data from 264,010 infants born in the United States between 1995 and 2003, it was proposed that $13 \%$ of asthma cases could be prevented by eliminating infant bronchiolitis during the RSV season [37].

Whilst it can be seen from the above that RSVH in early infancy is associated with an increased risk of long-term respiratory morbidity, other respiratory viruses, particularly rhinovirus, might be associated with a comparatively greater risk of wheezing/asthma $[33,46-49]$. In a study from Finland, Koponen et al. [33] reported that the risk of asthma was lower after RSV bronchiolitis than after bronchiolitis caused by other viruses (rhinovirus, influenza A virus, parainfluenza type 3 virus, adenovirus, human metapneumovirus, and unknown etiology) in infants hospitalized within the first 6 months of age $(8.2 \%$ vs. $24 \%$ in non-RSV patients; $P=0.01$ ) [33]. Other studies from Finland undertaken in the early 


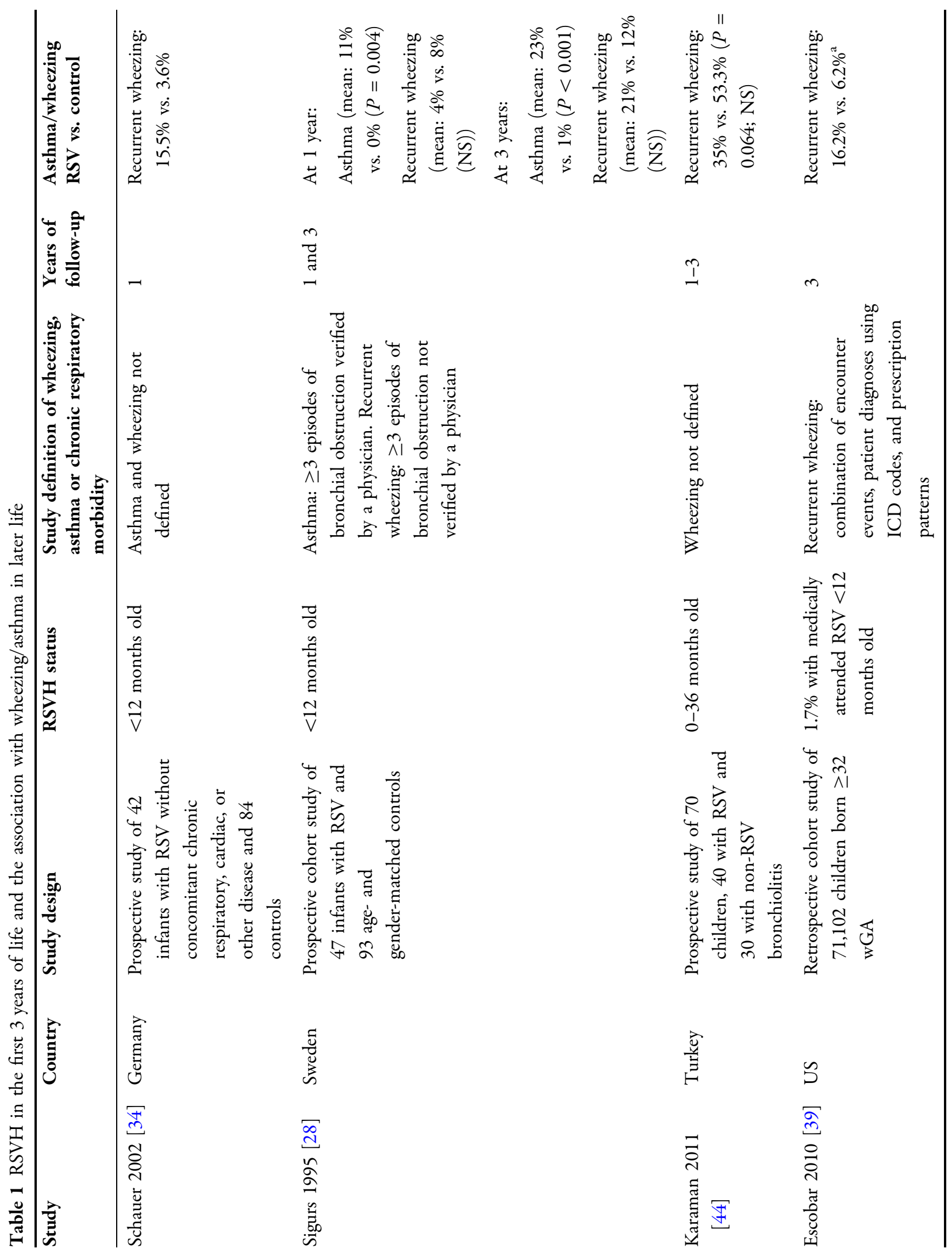




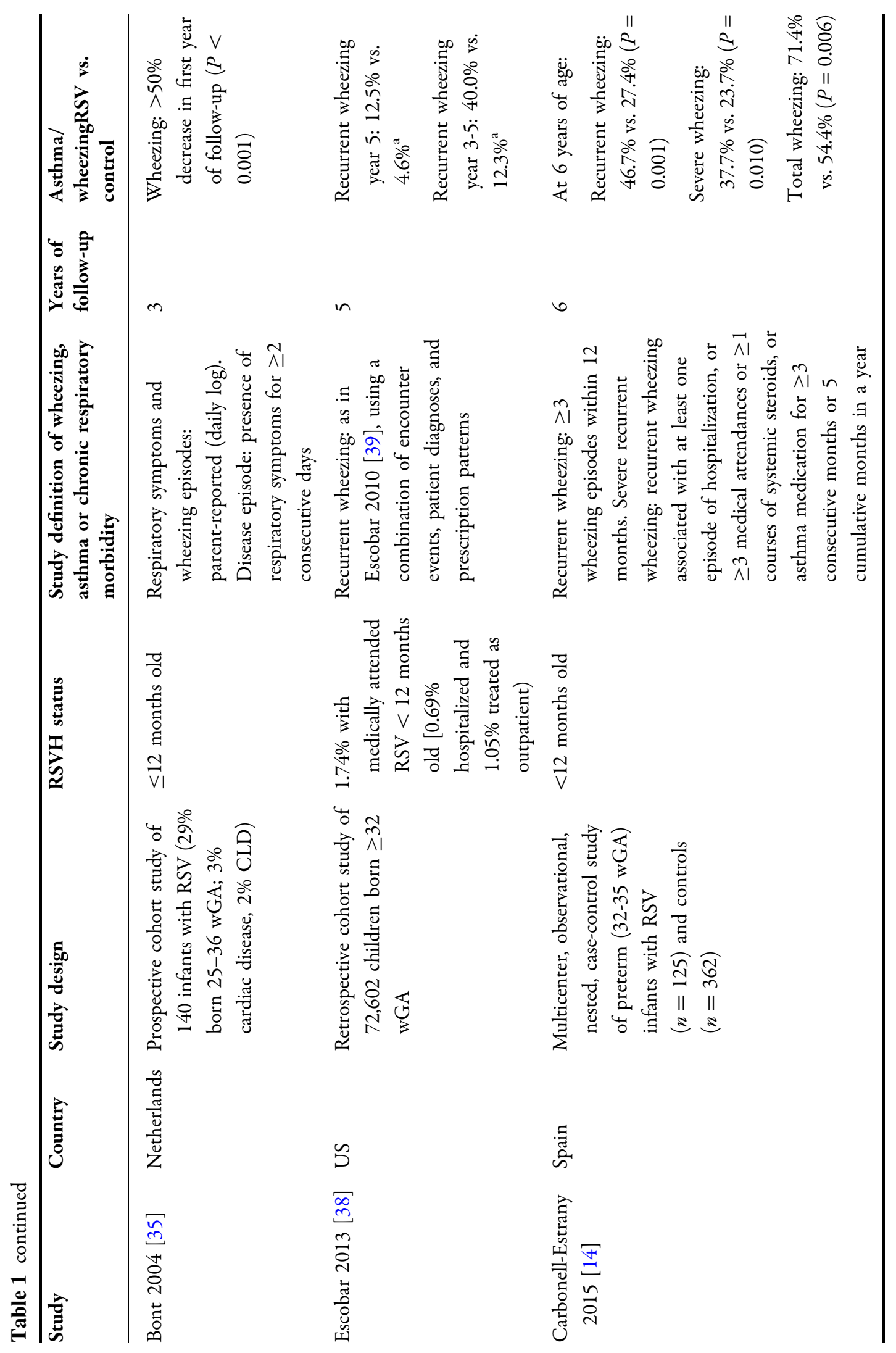




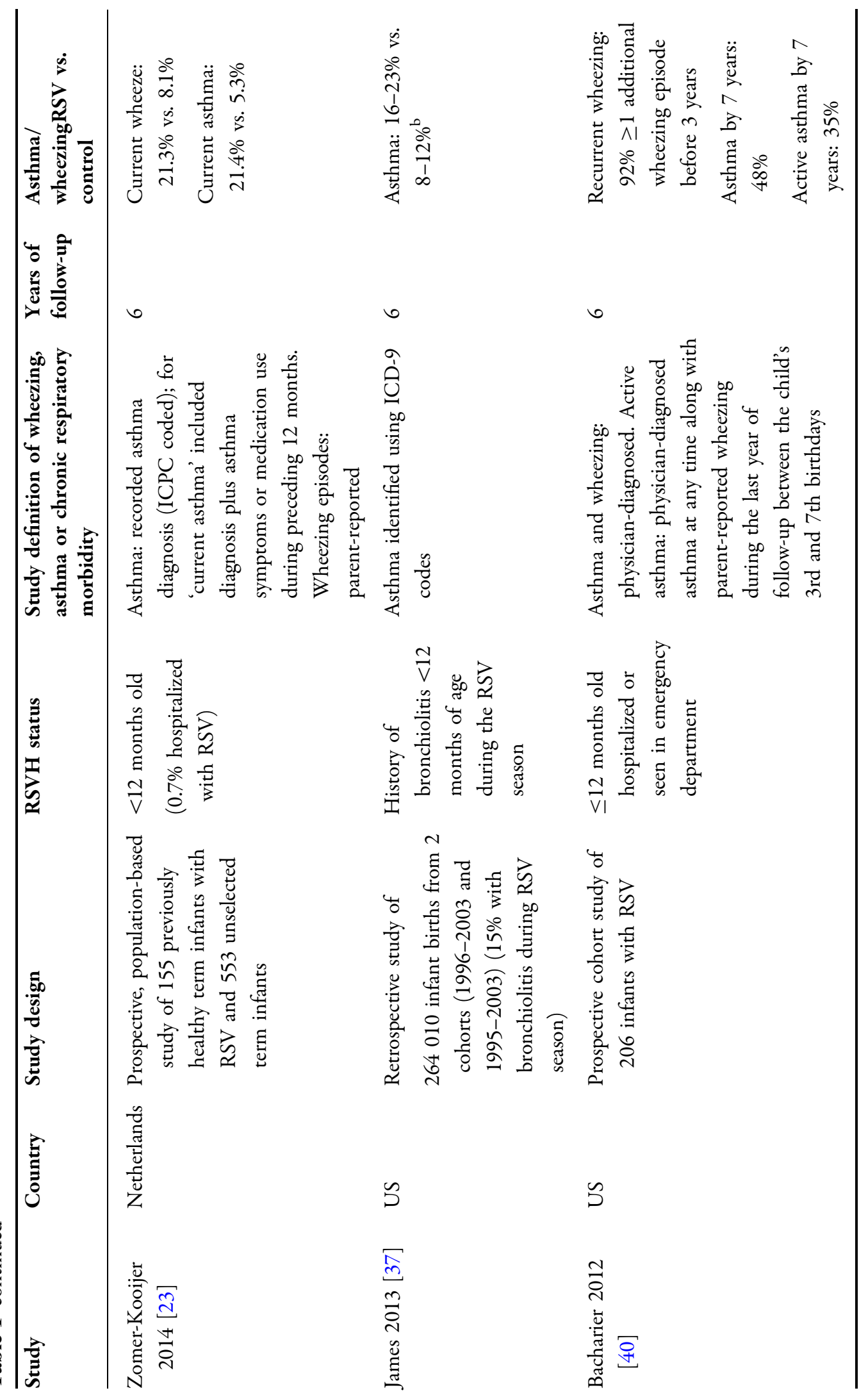




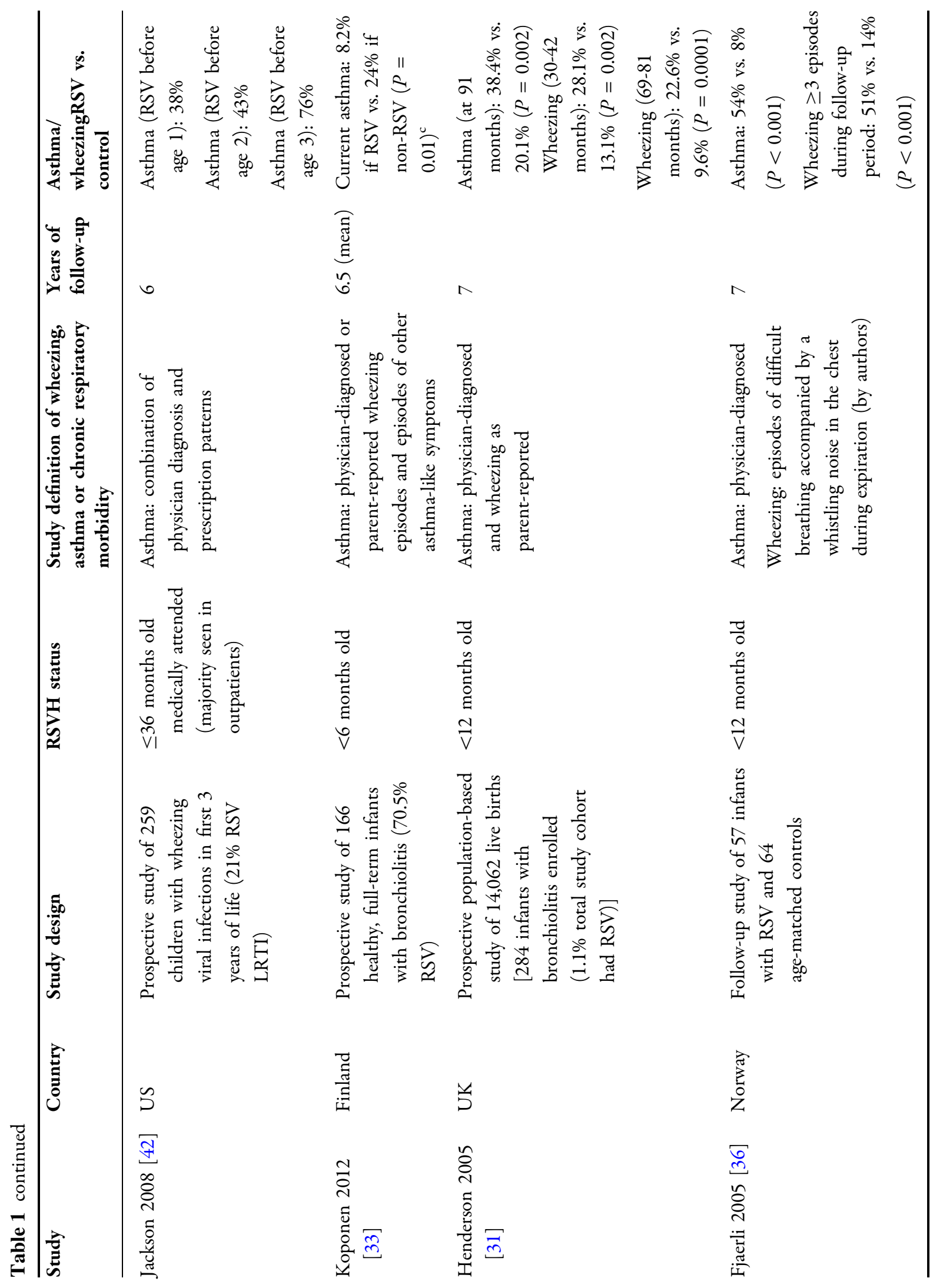




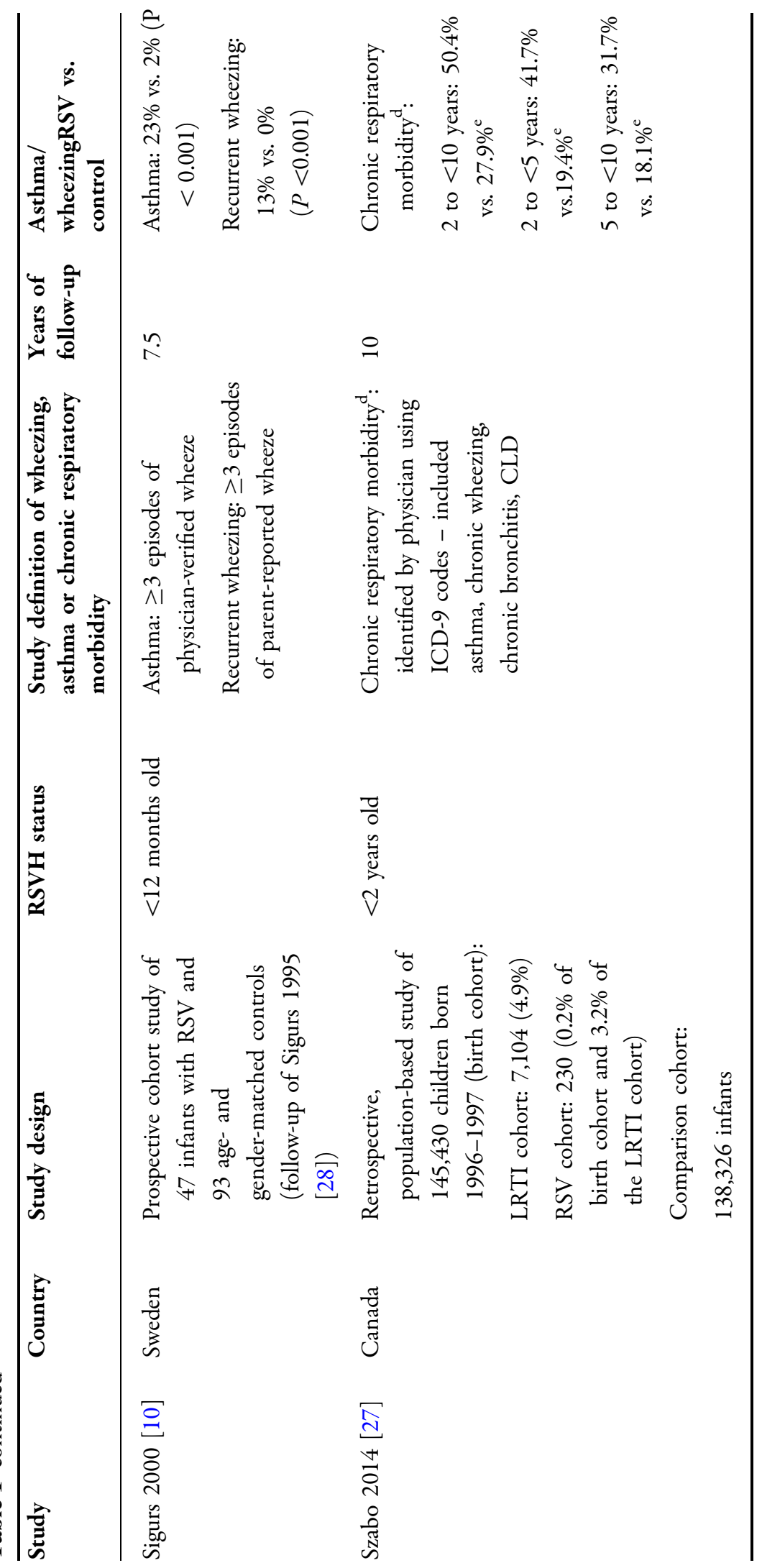




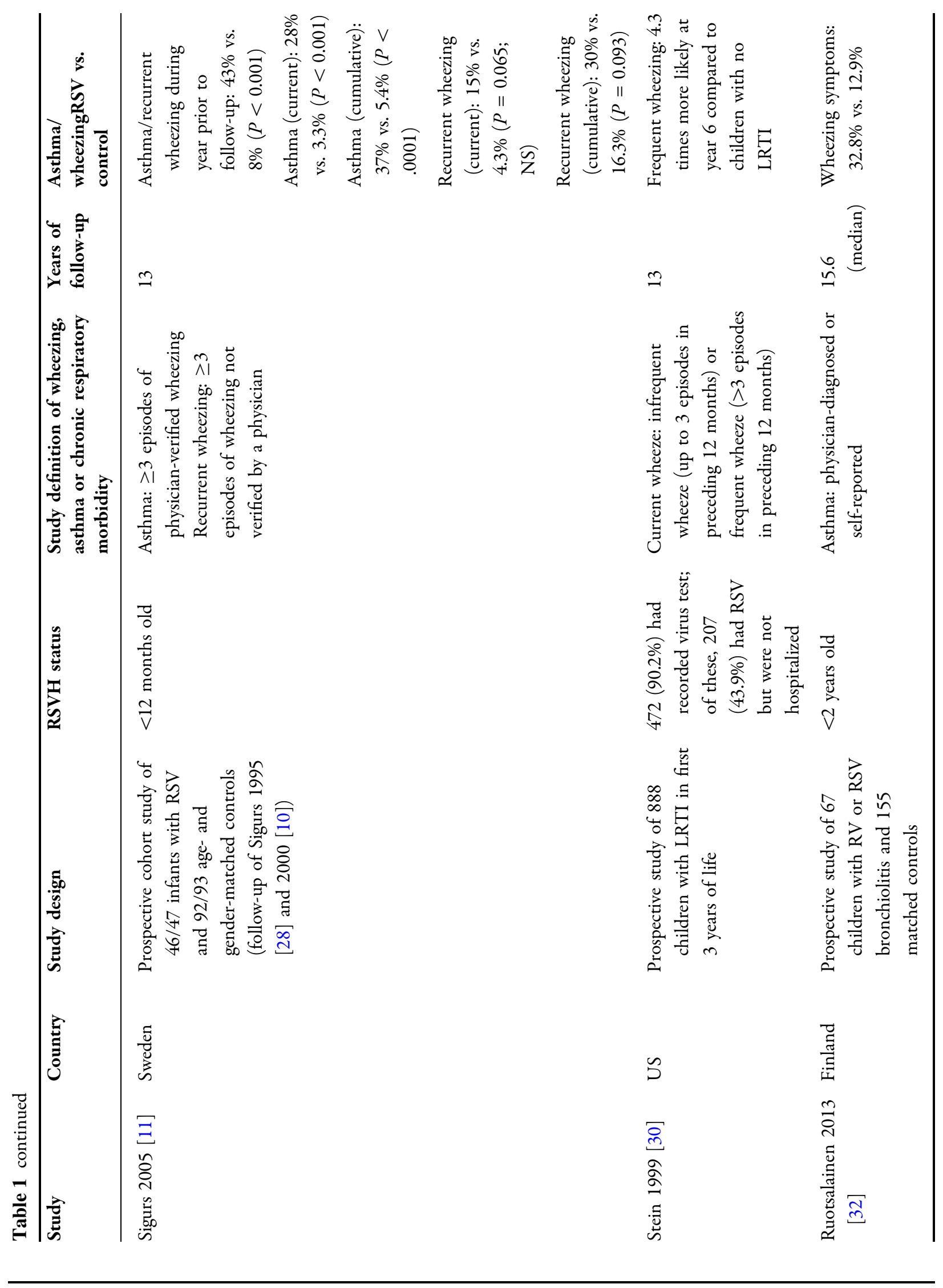




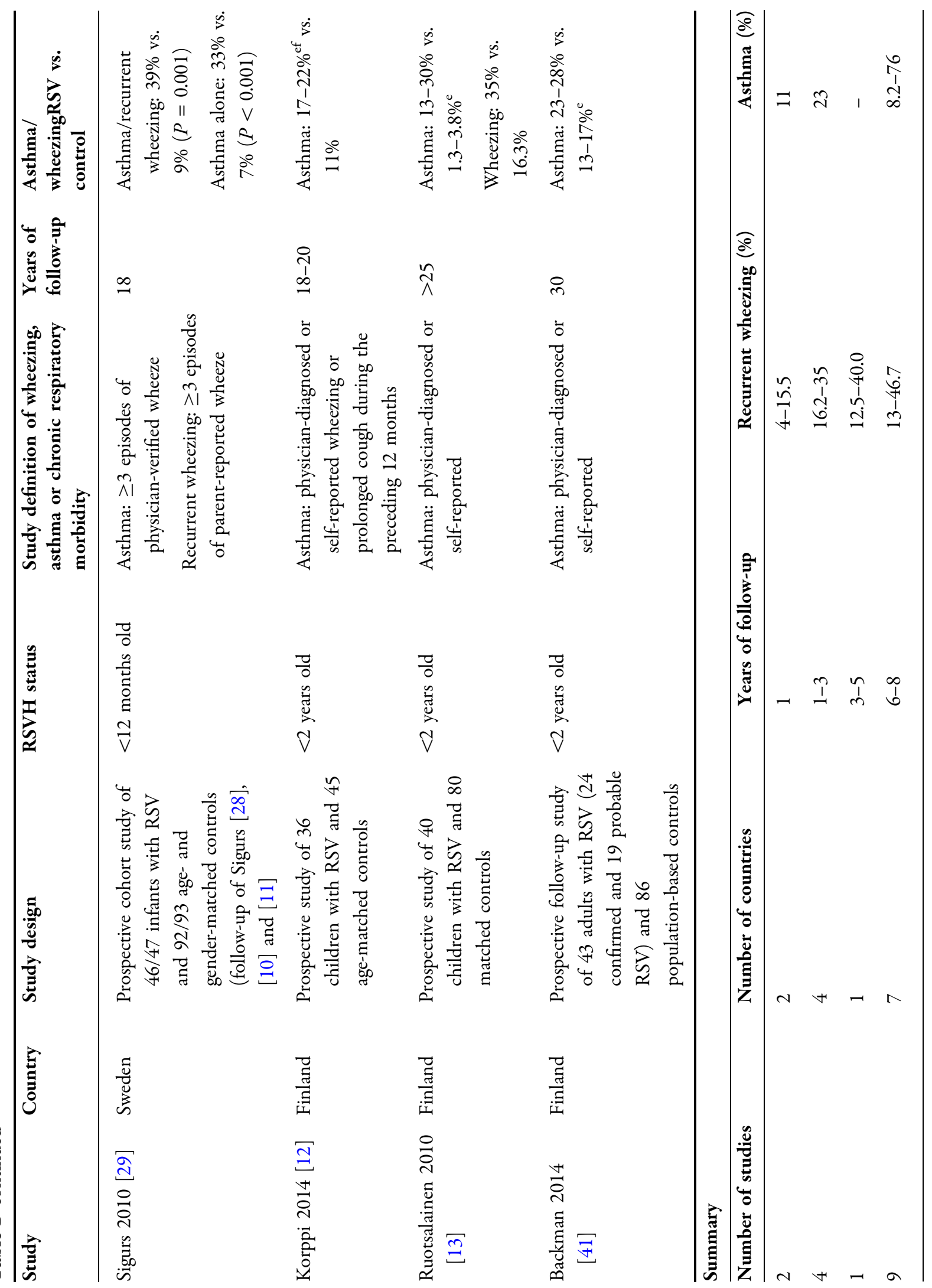




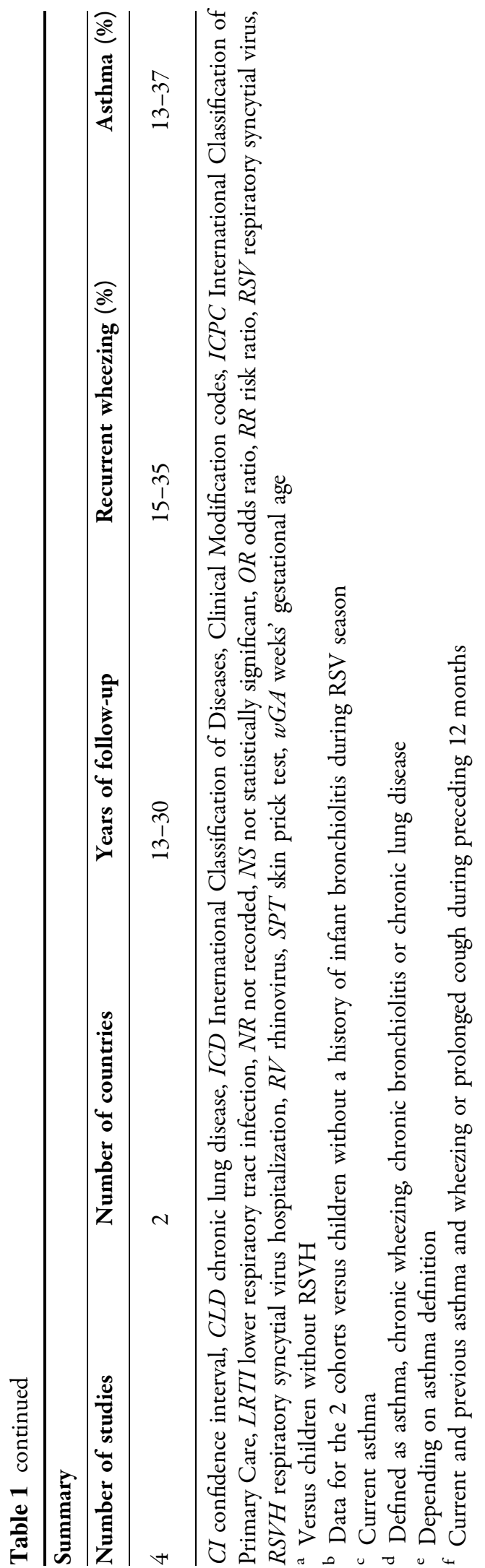

2000s [50, 51] suggest that the risk of early school-age asthma following RSVH might be of a similar order or slightly lower than that seen in children hospitalized with wheezing with no evidence of RSV (8-50\% vs. $45-57 \%$, respectively, depending on age at admission) [51]. Valkonen et al. [47] reported that Turkish children hospitalized with bronchiolitis caused by viruses other than RSV develop recurrent wheezing at substantially higher rates than do children with RSV-associated bronchiolitis. The risk of developing recurrent wheezing was significantly increased in the non-RSV group within the first 2 years [relative risk (RR), 2.9; 95\% CI, 1.7-5.1] and 3 years (RR, 3.4; 95\% CI, 2.0-5.7) after hospitalization [47]. A more recent study from Spain found that children aged $\geq 4$ years with a history of rhinovirus, metapneumovirus or bocavirus associated bronchiolitis had more hospital admissions for respiratory conditions than RSV-positive children for respiratory conditions (30\% vs. $17 \%$, respectively; $P=0.075$ ), persistent asthmatic symptoms $(25 \%$ vs. $7 \% ; P=0.003)$, and asthmatic exacerbations in the last year $(40 \%$ vs. $22 \% ; P=0.023$ ) [48]. Studies have indicated that the differences in risk of wheezing/asthma following RSV versus non-RSV bronchiolitis is not associated with differences in age, seasonal factors, prematurity, day-care attendance, atopic dermatitis, allergic sensitization, pulmonary function, smoke exposure, sex, or family history of asthma/allergic rhinitis [47-49].

The risk of asthma after bronchiolitis may be related to the severity of the first episode $[49,52,53]$. In a prospective study by Carroll et al. [52], $18 \%$ of children with clinically significant bronchiolitis during infancy accounted for $31 \%$ of children with early childhood asthma. In addition, the level of healthcare utilization during the bronchiolitis episode correlated with the risk of subsequent asthma, with the greatest risk of asthma following bronchiolitis hospitalization. Relative to children with no history of infant bronchiolitis, the adjusted ORs for asthma were 1.86 (95\% CI, 1.74-1.99), $2.41 \quad(2.21-2.62)$ and 2.82 (2.61-3.03) in the Outpatient, Emergency Department, and Hospitalization groups, respectively [52]. Al-Shawwa et al. [49] 
evaluated the potential effect of severity of RSV LRTI on subsequent wheezing in 155 children $<2$ years of age. Again, hospitalized patients were more likely to have recurrent wheezing compared with non-hospitalized patients (OR 2.84; 95\% CI, 1.24-6.50) [49].

\section{Long-term Respiratory Morbidity in Specific High-risk Groups}

\section{Premature Infants}

Infants born prematurely are at risk of RSV-related sequelae, including recurrent wheezing $[14,39,54-57]$. Data from a prospective study by Greenough et al. [56] demonstrated that chronic respiratory morbidity occurs in preterm infants born between 32 and 35 weeks' gestational age (wGA), regardless of whether their RSV infection required hospitalization. Escobar et al. [38] retrospectively studied 72,602 infants born at $\geq 32$ wGA. In total, $1.74 \%$ had a confirmed RSV infection $(0.69 \%$ were hospitalized and $1.05 \%$ were treated as an outpatient). Across all children, the prevalence of recurrent wheezing decreased over time from $5.6 \%$ during the second year of life to $4.7 \%$ during the fifth year of life. Three important risk factors (RSV disease in the first year of life, moderate prematurity and exposure to supplemental oxygen in the neonatal period) emerged to be significantly associated with the development of recurrent wheezing during the fifth year of life. The adjusted OR for prolonged RSVH was 2.59 (95\% CI, 1.49-4.50) [38]. Similarly, data from the SPRING study [14], a multicenter, observational, nested, case-control study undertaken in Spain, showed a decline in the incidence of wheezing with age. While the incidence of recurrent wheezing was higher in cases than in controls for each individual year of follow-up, the difference remained statistically significant only during the first 3 years of life (Table 2). However, when considering the overall proportion of cases and controls that experienced recurrent wheezing through 6 years of age, this was significantly greater in the former than the latter (46.7\% vs. $27.4 \%$, respectively; $P=0.001$ ). Multivariate analysis revealed that RSVH was the most important factor for wheezing (recurrent wheezing: OR, 4.40; 95\% CI, 2.82-6.86; $P<0.001$; severe wheezing: OR, 4.31; 95\% CI, 2.78-6.68; $P<0.001)$ [14].

A 12-month follow-up of the French CASTOR (Comparison of the rAte of hoSpitalization for RSV bronchioliTis between preterm infants born at 32 weeks' gestational age or less without brOnchopulmonary dysplasia and full-teRm infants) study cohort was undertaken to evaluate the respiratory morbidity of preterm infants $<33$ wGA without BPD during the subsequent 12-month period [54]. In this study, 242 preterm infants were compared with 201 full-term infants (39-41 wGA). Preterm infants had increased respiratory morbidity during the follow-up period compared with full-term infants; they were more likely to have wheezing ( $21 \%$ vs. $11 \%, P=0.007$ ) and recurrent wheezing ( $\geq 3$ episodes of within 12 months; $4 \%$ vs. $1 \%, P=0.049)$. The 17 infants (14 preterms, 3 full-terms) who had been hospitalized for RSV-confirmed LRTI during their first RSV season had significantly more wheezing episodes during the follow-up period than the infants who had not been hospitalized for RSV confirmed LRTI (OR, 4.72; 95\% CI, 1.71-13.08; $P=0.003)$ [54].

\section{Congenital Heart Disease}

Whilst it is well established that children with CHD are at risk for severe RSV LRTI, limited data are available on the long-term respiratory morbidity associated with RSVH in early life in this patient population. In a retrospective study of 3223 children with CHD, 19 (0.6\%) and 417 (12.9\%) were hospitalized for RSV or LRTI, respectively, before the age of 2 years [58]. Fifty-nine percent of children with CHD who were hospitalized for LRTI in infancy were diagnosed with chronic respiratory morbidity at the age of 10 years, as compared with $31.5 \%$ of children with CHD not hospitalized for LRTI in infancy [58].

\section{Down Syndrome}

Down syndrome is an independent risk factor for RSVH and severe RSV disease [59]. There are limited data, however, on long-term respiratory morbidity associated with RSV LRTI in early life 
Table 2 Incidence of recurrent wheezing years 2-6 in the SPRING study ${ }^{a}$ [14]

\begin{tabular}{|c|c|c|c|c|c|c|c|c|c|c|}
\hline \multirow[t]{2}{*}{ Wheezing } & \multicolumn{2}{|c|}{ Year 2} & \multicolumn{2}{|c|}{ Year 3} & \multicolumn{2}{|c|}{ Year 4} & \multicolumn{2}{|c|}{ Year 5} & \multicolumn{2}{|c|}{ Year 6} \\
\hline & $\mathrm{RSV}^{\mathbf{b}}$ & Control & $\mathbf{R S V}^{\mathbf{b}}$ & Control & $\overline{\mathbf{R S V}^{\mathbf{b}}}$ & Control & $\overline{\mathbf{R S V}^{\mathbf{b}}}$ & Control & $\overline{\mathbf{R S V}^{\mathbf{b}}}$ & Control \\
\hline Number of children (\%) & 41.4 & 12.1 & 29.3 & 15.4 & 18.5 & 12.6 & 15.0 & 9.3 & 12.4 & 9.7 \\
\hline$P$ & \multicolumn{2}{|l|}{$<0.001$} & \multicolumn{2}{|l|}{0.001} & \multicolumn{2}{|l|}{ NS } & \multicolumn{2}{|l|}{ NS } & \multicolumn{2}{|l|}{ NS } \\
\hline OR $(95 \% \mathrm{CI})$ & \multicolumn{2}{|c|}{$5.14(2.68-9.87)$} & \multicolumn{2}{|c|}{$2.28(1.41-3.70)$} & \multicolumn{2}{|c|}{$1.58(0.91-2.75)$} & \multicolumn{2}{|c|}{$1.72(0.92-3.20)$} & \multicolumn{2}{|c|}{$1.32(0.68-2.59)$} \\
\hline
\end{tabular}

$C I$ confidence interval, $N S$ not statistically significant, $O R$ odds ratio, $R S V$ respiratory syncytial virus

${ }^{a}$ For each individual year of follow-up, the number (proportion) of children with wheezing is shown, utilizing all available data for that particular year (therefore, the same child may be included in more than 1 year). Recurrent wheezing defined as $\geq 3$ episodes of wheezing within 12 months

b RSVH in preterm infants (32-35 weeks' gestational age) in first year of life

in children with Down syndrome. In a combined retrospective/prospective cohort study, Bloemers et al. [60] found that RSV LRTI did not significantly contribute to the risk of recurrent wheeze in children with Down syndrome (RSVH: $36 \%$ vs. non-hospitalized: 30\%; not statistically significant). Similar non-significant differences were found for parent-reported recurrent wheeze (42\% vs. 32\%, respectively) and physician-diagnosed asthma (11\% vs. $9 \%$, respectively). Physician-diagnosed wheeze, however, was more common in children with Down syndrome hospitalized for RSV LRTI than healthy controls $(31 \%$ vs. $8 \% ; P=0.004)$. The authors proposed that abnormal lung function or airway hyper-responsiveness, as well as an abnormal immunologic status, could play a role in the development of long-term airway morbidity in children with Down syndrome, irrespective of RSV status [60].

\section{Reduced Lung Function}

RSV LRTI in early life is associated with reduced lung function and increased airway reactivity at school age [11, 12, 30, 36, 61, 62], potentially extending into adulthood [12]. A prospective cohort study from the UK reported that viral LRTIs, regardless of hospitalization, adversely affect preterm infants' ( $<36 \mathrm{wGA}$ ) lung function at 12-month follow-up [63]. Longer-term data from the UK demonstrated that preterm infants $(<32$ wGA) who develop bronchopulmonary dysplasia (BPD) and are hospitalized for RSV infection in the first 2 years of life have significantly worse lung function at 8-10 years [62]. Similarly, the Tucson Children's Respiratory Study reported that children who had RSV LRTI before the age of 3 years had decreased lung function at school age [30]. In a prospective, 20-year follow-up study from Finland, at least one abnormal lung function result was observed in $44 \%$ of subjects who developed RSV LRTI in the first 2 years of life, compared with $31 \%$ of controls $(P<0.05)$ [12]. In addition, RSV LRTI in infancy was an independent risk factor for lung function abnormality [spirometric airway function (FVS; OR, 5.27, 95\% CI, 1.60-17.36) and also for decreased forced expiratory volume in $1 \mathrm{~s} \mathrm{FEV}_{1} / \mathrm{FVC}(\mathrm{FEV} \%)$ and mid-expiratory flow at 50\% of FVC (MEF50), when these were analyzed separately] [12]. At the 18-year follow-up of the study by Sigurs et al. [29], reduced spirometric airway function [1 s $\mathrm{FEV}_{1}$, ratio of $\mathrm{FEV}_{1}$ to $\mathrm{FVC}$, and forced expiratory flow at $\left.25-75 \% \mathrm{FVC}\left(\mathrm{FEF}_{25-75}\right)\right]$ was observed in the RSV cohort compared with controls. However, in contrast to the previous studies, a Finnish study indicated a potentially more restrictive pattern of lung function abnormality, documented by significantly decreased FVC values concomitantly with normal $\mathrm{FEV}_{1}$ values and even elevated $\mathrm{FEV}_{1} / \mathrm{FVC}$ values [64]. Finally, another recent study from Finland observed that less than $1 \%$ of 5 - to 7-year-old children, hospitalized for bronchiolitis caused mainly by RSV at age $<6$ months, had persistent lung function reduction [65].

It is unclear whether the abnormalities in lung function seen at follow-up result from the 
RSV infection itself or reflect premorbid abnormal lung function [62]. Studies from the Netherlands indicate that both hypotheses may be involved [66]. The MAKI trial has strongly implicated RSV infection as an important mechanism of recurrent wheeze during the first year of life in such infants [66]. A further study from the same group proposed that lower lung function in school-aged children that were previously hospitalized for RSV LRTI cannot only be attributed to the RSV infection itself, but might be partially pre-existent [67].

\section{Factors Associated with the Development of Recurrent Wheezing/Asthma after RSV LRTI in Early Life}

\section{Risk Factors}

Several risk factors associated with the development of asthma in children with a history of RSV LRTI in early life have been proposed by Cassimos et al. [68]. In this retrospective study, the development of asthma was independently associated with male gender [adjusted odds ratio (aOR), 5.0; 95\% CI, 2.2-11.5], breast-feeding $<3$ months (aOR, 8.4; 95\% CI, 3.1-22.4), living in a home environment with moisture damage (aOR, 2.9; 95\% CI, 1.3-6.3) and/or tobacco smoke by two or more residents (aOR, $4.9 ; 95 \% \mathrm{CI}, 1.8-9.2)$, and sensitization to at least one aeroallergen (aOR, 7.1; 95\% CI, 2.8-18.1). Lung function was significantly lower in children with RSV LRTI compared to a matched control group, even in children with a history of RSV LRTI who were not asthmatic [68].

The mechanisms underlying the interaction between RSV LRTI in infancy and active smoking as determinants of asthma in early adult life are unknown [69]. Further findings from the Tucson Children's Respiratory Study indicate that subjects with RSV LRTI during the first 3 years of life who actively smoke are at increased risk of having current asthma (95\% CI, 1.2-2.3; $P=0.003$ ) and increased peak flow variability (amplitude \% mean: $10.0 \%$ vs. $6.4 \%$; $P=0.02$ ) in adulthood, as compared with those who do not smoke [69]. The authors suggest that their findings support the potential interactive role of early-life insult by RSV and subsequent active cigarette smoking on the development of obstructive lung diseases, such as asthma and chronic obstructive pulmonary disease (COPD), in later life [69].

\section{Atopy and Allergy}

There are limited and conflicting data on the association between RSV LRTI in early life and the subsequent development of clinical allergy and/or allergic sensitization. Sigurs et al. [10, 11] demonstrated that RSV severe enough to cause hospitalization was significantly associated with the development of allergic sensitization up to the age of 13 years. Multivariate analyses of possible risk factors for sensitization showed that RSV LRTI was a significant independent risk factor for allergic sensitization (OR, 2.4; 95\% CI, 1.1-5.5) [10]. Similarly, Schauer et al. [34] found RSV LRTI to be the single most important risk factor for sensitization (OR, 20.66; 95\% CI, 3.53-120.75). In the study by Korppi et al. [12], the presence of asthma, bronchial reactivity, and lung function abnormalities after RSV infection in infancy were clearly associated with atopy, as defined by skin test responses to common inhaled allergens. Several other studies, however, did not find an association between RSV infection and subsequent atopy [30, 31, 41, 70]. Stein et al. [30] found no link between the incidence of RSV LRTI in early life and the subsequent development of atopic sensitization. Henderson et al. [31] also did not observe a significant association between RSV LRTI in infancy and allergic sensitization to aeroallergens at age 7 years. Finally, Strannegård et al. [71] reported that RSV LRTI may be an important risk factor for later development of atopic disease, but the authors could not exclude that bronchiolitis simply serves as a marker that predicts later development of atopy.

\section{Genetic Factors}

Not all children exposed to RSV experience subsequent wheezing, suggesting that genetic factors may also play a role in this phenomenon [72]. Several studies have therefore aimed to identify genetic determinants of recurrent wheeze after RSV LRTI [72-77]. 
Results of a multicenter cohort study by Schuurhof et al. [73] found that the production of IL10 by monocytes after RSV infection is higher in patients with recurrent wheezing than in patients without wheezing [74]. In a 6-year, prospective, follow-up study of 101 children hospitalized for RSV LRTI at $\leq 12$ months of age, the IL-13 Gln allele was found to be associated with late wheezing (OR, 3.27; 95\% CI, 1.32-8.06), but not with early wheezing [75]. The IL8 polymorphism was not shown to be related to either early or late wheezing after RSV LRTI in this study [75]; however, it was found to be related to wheezing and RSV LRTI in a study by Goetghebuer et al. [77]. In a subsequent study by Ermers et al. [76], the genetic variation in adaptive immunity genes, and particularly in IL10 family member genes IL19 and IL20 genes, seemed to be associated with recurrent wheeze after RSV LRTI, and perhaps infant wheeze in the general population. This suggests a role for IL19 and IL20 cytokines in airway disease.

A more recent study from the United States demonstrated that rare nonsynonymous variants contribute to the development of asthma following severe RSV LRTI in infancy, notably $A D R B 2$. Torgerson et al. [72] performed pooled, anonymous, sequencing of coding exons from 131 asthma candidate genes in 182 individuals (99 European Americans and 83 African Americans) with severe RSV LRTI in infancy from the REBEL study [40] for variant discovery, and then directly genotyped a set of 190 nonsynonymous variants. Four rare, nonsynonymous variants were found to be significantly associated with asthma following severe RSV LRTI, including single variants in ADRB2, FLG and NCAM1 in European Americans $\left(P=4.6 \times 10^{-4}\right.$, $1.9 \times 10^{-13}$ and $5.0 \times 10^{-5}$, respectively), and NOS1 in African Americans $\left(P=2.3 \times 10^{-11}\right)$ [72]. Additional studies are needed to confirm these associations and determine the functional consequences of these genetic variants.

Three population-based studies of twins, undertaken in Denmark utilizing bronchiolitis information from patient registries, assessed causality between RSV infection in infancy and childhood asthma [16, 78, 79]. Thomsen et al. [78] reported that RSV infection severe enough to require hospitalization did not appear to cause asthma but was an indicator of the genetic predisposition to asthma. Stensballe et al. [79] reported that asthma hospitalization after RSVH was increased as much as six- to eight-fold during the first 2 months after RSVH but not 1 year later. A further study of 37 monozygotic twin pairs discordant for severe RSV bronchiolitis in infancy indicated no differential effect of severity of RSV infection on the development of asthma [16].

\section{Altered Immunology}

One of the specific characteristics of asthma is an imbalance in Th1- and Th2-predominant immune responses [80]. Castro et al. [80] hypothesized that severe RSV infection resulting in bronchiolitis may stimulate a persistent Th2 response profile with elevated IL4 and IL13 production at 6 years of age in those children who developed asthma. Two hundred and six previously healthy infants hospitalized for a first episode of RSV LRTI were enrolled into the REBEL cohort study and followed prospectively through 6 years of age. Th1 cytokines tended to decrease over time after initial severe RSV bronchiolitis and Th2 cytokines tended to increase over time, but these patterns were unrelated to asthma and allergy outcomes. No significant difference in Th1 or Th2 cytokine production at the initial RSV infection was observed in those who developed asthma or allergic sensitization by 6 years of age as compared to those who did not. Furthermore, the production of Th2 cytokines relative to Th1 cytokines, represented by the ratio of IL4: IFN- $\gamma$, was not different in those who developed asthma compared to those who did not. Th1 cytokines tended to decrease over time after initial severe RSV bronchiolitis and Th2 cytokines tended to increase over time but these patterns were unrelated to asthma and allergy outcomes [80].

Plasmacytoid dendritic cells play a crucial role in antiviral immunity and promoting Th1 polarization, possibly protecting against development of allergic disease [81]. Silver et al. [81] showed that children with a history of severe RSV LRTI in early life and physician-diagnosed asthma by age 6 years appear to have a relative deficiency of plasmacytoid dendritic cells in 
peripheral blood compared to those who were not diagnosed with asthma. Further data from a recent prospective study demonstrated that children with recurrent wheezing following severe RSV LRTI had a higher proportion of nasal plasmacytoid dendritic cells, which may reflect a heightened antiviral response in the airway leading to the subsequent development of asthma [82]. Further studies are therefore needed to confirm these findings.

Researchers have also evaluated the relationship between viral load in infants hospitalized for RSV and recurrent wheezing later in childhood. Nenna et al. [83] observed higher RSV-RNA load and significant correlations between RSV-RNA load and higher interferon- $\lambda 1 / 2 / 3$ levels in children previously hospitalized for RSV LRTI and diagnosed with recurrent wheezing at 3 years follow-up.

\section{Eosinophilia}

Several studies have shown that eosinophilia at the time of bronchiolitis is associated with a higher risk of developing persistent wheezing in later childhood [84-87]. Calvo Rey et al. [84] reported that eosinophil values of $>1 \%$ during an episode of acute bronchiolitis in infancy was associated with a higher risk of developing persistent wheezing in the first 5 years of life. Ehlenfield et al. [85] retrospectively studied 43 infants hospitalized with RSV LRTI at $\leq 18$ months old. Of children who had eosinophilia with RSV LRTI, $56 \%$ had persistent wheezing at 7 years of age compared with $22 \%$ without detectable eosinophilia with RSV LRTI $(P=0.045)$ [84]. In a further study, Pifferi et al. [86] observed significantly higher serum eosinophil cationic protein levels $(P<0.001)$ at enrolment in infants with RSV LRTI who developed persistent wheezing 5 years later compared with subjects who did not develop late wheezing. Similarly, Kristjánsson et al. [87] reported that a high level of urinary eosinophil protein $\mathrm{X}$ appeared to increase the risk of future wheezing in children hospitalized for RSV LRTI.

\section{Maternal Antibody}

A case-cohort study undertaken in Denmark examined the influence of maternally derived RSV neutralizing antibodies on the risk of RSVH and recurrent wheeze using data from The Danish National Birth Cohort and the RSV Database [88]. Stensballe et al. [88] identified 2562 children with RSVH and 6153 children with recurrent wheeze. One of the main findings of the study was that the titer of maternally derived RSV neutralizing antibodies in cord blood was associated with an increased risk of recurrent wheeze in children both with and without RSVH [88].

\section{Long-term Respiratory Morbidity and Impact on Quality of Life and Cost of Care}

RSV LRTI is associated with subsequent decreased QoL and increased healthcare costs $[14,15,41]$, although data remain limited. In the SPRING study [14], the respiratory subscale QoL of the preschool children Quality of Life questionnaire (TAPQOL) was significantly lower $(P=0.001)$ through 6 years of age in preterm infants born 32-35 wGA hospitalized for RSV infection in the first year of life than in controls. Backman et al. [41] also reported that, on average, former RSV patients had a lower respiratory health-related quality of life (HRQoL) on the St George's Respiratory Questionnaire (components: symptoms, activity, impact), at 28-31 years of age than population-based controls. The difference was mainly seen in the symptoms score $(P=0.005)$ [41]. In an earlier study, Bont et al. [15] reported that HRQoL at 3 years of age was attributed to post-bronchiolitis wheezing, but not to pre-existent risk factors, such as age, gender and premature birth. In addition to these studies, two further studies from Norway demonstrated that being hospitalized for acute bronchiolitis (specific virus not stated) in infancy was significantly associated with later reduced QoL and that disease severity appeared to negatively influence 
the QoL of the infants and the parental perception of the child's health 9 months later $[89,90]$.

Healthcare resource utilization was significantly higher $(P<0.001)$ through 6 years of age in cases than controls in the SPRING study [14]. Greenough et al. [91] reported that preterm infants who had had CLD had a greater number of outpatient attendances for respiratory problems (mean 2.52 vs. $0.85 ; P=0.007$ ). In addition, the cost of care was significantly greater for outpatient attendances, including those for respiratory problems [91]. A further study by Greenough et al. [62], that enrolled the same cohort of children, found that those who were hospitalized for RSV in the first 2 years after birth had more outpatient attendances and a greater related cost of care between the ages of 5-7 and worse lung function than children not admitted in the first 2 years for a respiratory cause. Healthcare utilization, however, decreased with increasing postnatal age regardless of RSVH status [61].

\section{Limitations}

There are several key limitations of this review that should be recognized, most notably the variability in defining wheeze and asthma between studies, which restricts cross-study comparisons. Allied to this are the differences in frequency and length of follow-up between studies and the relatively limited amount of prospective data beyond 7-8 years after the index RSVH. Differences in study populations in terms of the presence of underlying comorbidities and prematurity, for example, also complicate interpretation of the results. The confounding influence of co-infections, which were infrequently documented in studies, might also in part account for discrepancies in findings among studies. Improvements over time in both medical and surgical practice and RSV surveillance may also influence interpretation of the results.

\section{Key statements/findings}

There is increasing evidence that RSV LRTI in early life is a significant risk factor for subsequent recurrent wheezing/asthma, persisting at least through early childhood

Recurrent wheezing rates of $4-47 \%$ and asthma rates of $8-76 \%$ have been reported in studies with up to 25 years follow-up (average follow-up 6-8 years)

RSV LRTI in early life is associated with reduced lung function and increased airway reactivity

Abnormalities reported for spirometric airway function include reduced $\mathrm{FEV}_{1}, \mathrm{FEV}_{1} / \mathrm{FVC}$, and $\mathrm{FEF}_{25-75}$

RSV-related respiratory morbidity may be related to a combination of the viral insult, preexisting abnormal lung function and/or other factors predisposing for wheezing/asthma

Other factors include: genetics (e.g. increased production of IL10), altered immunology (e.g., altered plasmacytoid dendritic cell levels), eosinophilia, transfer of maternally derived RSV antibody, and other risk factors (e.g., tobacco smoke exposure)

There is conflicting evidence on the association between RSV LRTI in early life and the subsequent development of clinical allergy and/or allergic sensitization

RSV LRTI is associated with decreased quality of life and increased healthcare costs, although data are limited

\section{Level of evidence ${ }^{\text {a }}$}

Level 1

(Level 1 studies: $n=21$;

Risk of bias ${ }^{\text {b }}$ : very low)

Level 1

(Level 1 studies: $n=8$; Risk of bias ${ }^{\text {b }}$ : very low)

Level 1

(Level 1 studies: $n=17$; Risk of bias ${ }^{\text {b }}$ : very low)

Level 1

(Level 1 studies: $n=7$; Risk of bias ${ }^{\text {b }}$ : very low)

Level 1

(Level 1 studies: $n=6$;

Risk of bias ${ }^{\text {b }}$ very low) 
continued

Key statements/findings

Level of evidence $^{a}$

Key areas for research:

Further prospective, follow-up studies are needed to clarify the risk factors and long-term respiratory outcome of children hospitalized for severe RSV LRTI (including in specific populations, such as those with CHD, and the potential link with COPD/emphysema)

Future research should aim to elucidate the pathophysiological mechanisms through which RSV LRTI causes recurrent wheezing/asthma

$C H D$ congenital heart disease, $C I$ confidence interval, $F E V_{1}$ forced expiratory volume in one second, $F E V_{1} / F V C$ percentage of the vital capacity which is expired in the first second of maximal expiration, $F E F_{25-75}$ forced expiratory flow at $25-75 \%$ of the pulmonary volume, $L R T I$ lower respiratory tract infection, $N S$ not statistically significant, $O R$ odds ratio, $R S V$ respiratory syncytial virus

${ }^{a}$ Level 1 local and current random sample surveys (or censuses); Level 2 systematic review of surveys that allow matching to local circumstances; Level 3 local non-random sample; Level 4 case-series [24, 25]

$\mathrm{b}$ Average RTI Item Bank Score [26], where $\leq 2=$ very high risk of bias and 10-12 = very low risk of bias

\section{CONCLUSIONS}

There is a growing body of evidence to suggest that RSV LRTI, regardless of hospitalization status, is a significant risk factor for on-going respiratory morbidity characterized by transient early wheezing and recurrent wheezing within the first decade of life and possibly into adulthood. These infants are also at increased risk of reduced pulmonary function and a higher risk or predisposition to asthma and allergies. The increased respiratory morbidity may lead to a reduced QoL and increased health care costs. It still remains unclear, however, whether RSV LRTI causes respiratory morbidity and/or serves as a marker for those infants genetically predisposed to develop asthma or wheezing. Further prospective, follow-up studies are needed to clarify the risk factors and long-term respiratory outcome of children hospitalized for severe RSV LRTI. Future research should aim to elucidate the pathophysiological mechanisms through which RSV LRTI causes recurrent wheezing/asthma.

\section{ACKNOWLEDGEMENTS}

Sponsorship and article processing charges for this study were funded by AbbVie. Joanne
Smith, Julie Blake (Reviewers 1 and 2) and Barry Rodgers-Gray (Reviewer 3), from Strategen Limited, undertook the systematic review following the protocol approved by the authors. All named authors meet the International Committee of Medical Journal Editors (ICMJE) criteria for authorship for this manuscript, take responsibility for the integrity of the work as a whole, and have given final approval to the version to be published. Editorial assistance in the preparation of this manuscript was provided by Julie Blake and Barry Rodgers-Gray. Support for this assistance was funded by AbbVie.

Disclosures. The institute of Louis Bont received money for investigator initiated studies by MeMed, AstraZeneca, AbbVie, and Janssen. The institute of Louis Bont received money for consultancy by AstraZeneca, AbbVie, MedImmune, Janssen, Gilead and Novavax. Paul Checchia has acted as an expert advisor and speaker for AbbVie and has received honoraria in this regard. He has also received research grant funding from AstraZeneca. Brigitte Fauroux has received compensation as a neonatology board member from AbbVie. Josep Figueras-Aloy has acted as an expert advisor and speaker for AbbVie and has received honoraria in this regard. Paolo Manzoni has acted as a speaker for AbbVie, and as an expert advisor for 
AbbVie, TEVA, Medimmune, AstraZeneca, Janssen, and has received honoraria in this regard. Bosco Paes has received research funding from AbbVie Corporation and compensation as an advisor or lecturer from AbbVie and MedImmune. Eric Simões has received grant funding to his institution from Medimmune Inc., Glaxo Smith Kline Inc., and received consultancy fees to the institution, from AbbVie. Xavier Carbonell-Estrany has acted as an expert advisor and speaker for AbbVie and has received honoraria in this regard.

Compliance with Ethics Guidelines. The analysis in this review article is based on previously published studies and does not involve any new studies of human subjects performed by any of the authors.

Data Availability. All data generated or analyzed during this study are included in this published article/as supplementary information files.

Open Access. This article is distributed under the terms of the Creative Commons Attribution-NonCommercial 4.0 International License (http://creativecommons.org/licenses/ by-nc/4.0/), which permits any noncommercial use, distribution, and reproduction in any medium, provided you give appropriate credit to the original author(s) and the source, provide a link to the Creative Commons license, and indicate if changes were made.

\section{REFERENCES}

1. Nair H, Nokes DJ, Gessner BD, Dherani M, Madhi SA, Singleton RJ, et al. Global burden of acute lower respiratory infections due to respiratory syncytial virus in young children: a systematic review and meta-analysis. Lancet. 2010;375:1545-55.

2. Seglani S. Viral infections and the development of asthma in children. Ther Adv Infect Dis. 2013;1:139-50.

3. Piedimonte G. Respiratory syncytial virus and asthma: speed-dating or long-term relationship? Curr Opin Pediatr. 2013;25:344-9.
4. Thorburn K. Pre-existing disease is associated with a significantly higher risk of death in severe respiratory syncytial virus infection. Arch Dis Child. 2009;94:99-103.

5. Hervás D, Reina J, Yañez A, del Valle JM, Figuerola J, Hervás JA. Epidemiology of hospitalization for acute bronchiolitis in children: differences between RSV and non-RSV bronchiolitis. Eur J Clin Microbiol Infect Dis. 2012;31:1975-81.

6. Murray J, Bottle A, Sharland M, Modi N, Aylin P, Majeed A, Saxena S, Medicines for Neonates Investigator Group. Risk factors for hospital admission with RSV bronchiolitis in England: a population-based birth cohort study. PLoS ONE. 2014;9:e89186.

7. Hall CB, Weinberg GA, Iwane MK, Blumkin AK, Edwards KM, Staat MA, et al. The burden of respiratory syncytial virus infection in young children. N Engl J Med. 2009;360:588-98.

8. Hall CB. The burgeoning burden of respiratory syncytial virus among children. Infectious disorders-drug. Targets. 2012;12:92-7.

9. Hall CB, Weinberg GA, Blumkin AK, Edwards KM, Staat MA, Schultz AF, et al. Respiratory syncytial virus-associated hospitalizations among children less than 24 months of age. Pediatrics. 2013;132:e341-8.

10. Sigurs N, Bjarnason R, Sigurbergsson F, Kjellman B. Respiratory syncytial virus bronchiolitis in infancy is an important risk factor for asthma and allergy at age 7. Am J Respir Crit Care Med. 2000;161:1501-7.

11. Sigurs N, Gustafsson PM, Bjarnason R, Lundberg F, Schmidt S, Sigurbergsson F, et al. Severe respiratory syncytial virus bronchiolitis in infancy and asthma and allergy at age 13. Am J Respir Crit Care Med. 2005;171:137-41.

12. Korppi M, Piippo-Savolainen E, Korhonen K, Remes S. Respiratory morbidity 20 years after RSV infection in infancy. Pediatr Pulmonol. 2004;38:155-60.

13. Ruotsalainen M, Piippo-Savolainen E, Hyvärinen MK, Korppi M. Respiratory morbidity in adulthood after respiratory syncytial virus hospitalization in infancy. Pediatr Infect Dis J. 2010;29:872-4.

14. Carbonell-Estrany X, Pérez-Yarza EG, García LS, Guzmán Cabañas JM, Bòria EV, Atienza BB, IRIS Study Group. Long-term burden and respiratory effects of respiratory syncytial virus hospitalization in preterm infants-the SPRING study. PLOS ONE. 2015;10:e0125422.

15. Bont L, Steijn M, Van Aalderen WM, Kimpen JL. Impact of wheezing after respiratory syncytial virus 
infection on health-related quality of life. Pediatr Infect Dis J. 2004;23:414-7.

16. Poorisrisak P, Halkjaer LB, Thomsen SF, Stensballe LG, Kyvik KO, Skytthe A, et al. Causal direction between respiratory syncytial virus bronchiolitis and asthma studied in monozygotic twins. Chest. 2010;138:338-44.

17. Bont L, Checchia P, Fauroux B, Figueras-Aloy J, Manzoni P, Paes B, et al. Defining the epidemiology and burden of severe respiratory syncytial virus infection among infants and children in Western Countries. Infect Dis Ther. 2016;5:271-98.

18. Figueras-Aloy J, Manzoni P, Paes B, Simões EA, Bont L, Checchia PA, et al. Defining the risk and associated morbidity and mortality of severe respiratory syncytial virus infection among preterm infants without chronic lung disease or congenital heart disease. Infect Dis Ther. 2016;5:417-52.

19. Paes B, Fauroux B, Figueras-Aloy J, Bont L, Checchia PA, Simões EA, et al. Defining the risk and associated morbidity and mortality of severe respiratory syncytial virus infection among infants with chronic lung disease. Infect Dis Ther. 2016;5:453-71.

20. Checchia PA, Paes B, Bont L, Manzoni P, Simões EA, Fauroux B, et al. Defining the risk and associated morbidity and mortality of severe respiratory syncytial virus infection among infants with congenital heart disease. Infect Dis Ther. 2017;6:37-56.

21. International Statistical Classification of Diseases and Related Health Problems 10th Revision (ICD-10) version 2010. Available at: http://apps. who.int/classifications/icd10/browse/2010/en Accessed Nov 2016.

22. Verbeke M, Schrans D, Deroose S, De Maeseneer J. The International Classification of Primary Care (ICPC-2): an essential tool in the EPR of the GP. Stud Health Technol Inform. 2006;124:809-14.

23. Zomer-Kooijker $\mathrm{K}$, van der Ent CK, Ermers MJ, Uiterwaal CS, Rovers MM. Bont LJ; RSV Corticosteroid Study Group. Increased risk of wheeze and decreased lung function after respiratory syncytial virus infection. PLoS ONE. 2014;9:e87162.

24. OCEBM Levels of Evidence Working Group. "The Oxford 2011 Levels of Evidence". Oxford Centre for Evidence-Based Medicine. http://www.cebm.net/ index.aspx?o=5653 Accessed Mar 2016.

25. OCEBM Levels of Evidence Working Group. "The Oxford 2009 Levels of Evidence". Oxford Centre for Evidence-Based Medicine http://www.cebm.net/ oxford-centre-evidence-based-medicine-levels-evid ence-march-2009/ Accessed Mar 2016.
26. Viswanathan M, Berkman ND, Dryden DM, L Hartling. Assessing risk of bias and confounding in observational studies of interventions or exposures: further development of the RTI item bank. Methods Research Report. AHRQ Publication No. 13-EHC106-EF. Rockville, MD: Agency for Healthcare Research and Quality; August 2013. www.effecti vehealthcare.ahrq.gov/reports/final.cfm Accessed Mar 2016.

27. Szabo SM, Gooch KL, Korol EE, Bradt P, Mitchell I, Vo P, et al. A population-based study of childhood respiratory morbidity after severe lower respiratory tract infections in early childhood. J Pediatr. 2014;165:123-8.e3.

28. Sigurs N, Bjarnason R, Sigurbergsson F, Kjellman B, Björkstén B. Asthma and immunoglobulin E antibodies after respiratory syncytial virus bronchiolitis: a prospective cohort study with matched controls. Pediatrics. 1995;95:500-5.

29. Sigurs N, Aljassim F, Kjellman B, Robinson PD, Sigurbergsson F, Bjarnason R, et al. Asthma and allergy patterns over 18 years after severe RSV bronchiolitis in the first year of life. Thorax. 2010;65:1045-52.

30. Stein RT, Sherrill D, Morgan WJ, Holberg CJ, Halonen $M$, Taussig LM, et al. Respiratory syncytial virus in early life and risk of wheeze and allergy by age 13 years. Lancet. 1999;354:541-5.

31. Henderson J, Hilliard TN, Sherriff A, Stalker D, Al Shammari N, Thomas HM. Hospitalization for RSV bronchiolitis before 12 months of age and subsequent asthma, atopy and wheeze: a longitudinal birth cohort study. Pediatr Allergy Immunol. 2005;16:386-92.

32. Ruotsalainen M, Hyvärinen MK, Piippo-Savolainen E, Korppi M. Adolescent asthma after rhinovirus and respiratory syncytial virus bronchiolitis. Pediatr Pulmonol. 2013;48:633-9.

33. Koponen P, Helminen M, Paassilta M, Luukkaala T, Korppi M. Preschool asthma after bronchiolitis in infancy. Eur Respir J. 2012;39:76-80.

34. Schauer U, Hoffjan S, Bittscheidt J, Köchling A, Hemmis S, Bongartz S, Stephan V. RSV bronchiolitis and risk of wheeze and allergic sensitisation in the first year of life. Eur Respir J. 2002;20:1277-83.

35. Bont L, Steijn M, Van Aalderen WM, Brus F, Th Draaisma JM, Van Diemen-Steenvoorde RA, et al. Seasonality of long term wheezing following respiratory syncytial virus lower respiratory tract infection. Thorax. 2004;59:512-6.

36. Fjaerli HO, Farstad T, Rød G, Ufert GK, Gulbrandsen $\mathrm{P}$, Nakstad B. Acute bronchiolitis in infancy as risk 
factor for wheezing and reduced pulmonary function by seven years in Akershus County, Norway. BMC Pediatr. 2005;5:31.

37. James KM, Gebretsadik T, Escobar GJ, Wu P, Carroll $\mathrm{KN}$, Li SX, et al. Risk of childhood asthma following infant bronchiolitis during the respiratory syncytial virus season. J Allergy Clin Immunol. 2013;132:227-9.

38. Escobar GJ, Masaquel AS, Li SX, Walsh EM, Kipnis P. Persistent recurring wheezing in the fifth year of life after laboratory-confirmed, medically attended respiratory syncytial virus infection in infancy. BMC Pediatr. 2013;13:97.

39. Escobar GJ, Ragins A, Li SX, Prager L, Masaquel AS, Kipnis P. Recurrent wheezing in the third year of life among children born at 32 weeks' gestation or later: relationship to laboratory-confirmed, medically attended infection with respiratory syncytial virus during the first year of life. Arch Pediatr Adolesc Med. 2010;164:915-22.

40. Bacharier LB, Cohen R, Schweiger T, Yin-Declue H, Christie C, Zheng J, et al. Determinants of asthma after severe respiratory syncytial virus bronchiolitis. J Allergy Clin Immunol. 2012;130:91-100.e3.

41. Backman K, Piippo-Savolainen E, Ollikainen $\mathrm{H}$, Koskela H, Korppi M. Adults face increased asthma risk after infant RSV bronchiolitis and reduced respiratory health-related quality of life after RSV pneumonia. Acta Paediatr. 2014;103:850-5.

42. Jackson DJ, Gangnon RE, Evans MD, Roberg KA, Anderson EL, Pappas TE, et al. Wheezing rhinovirus illnesses in early life predict asthma development in high-risk children. Am J Respir Crit Care Med. 2008;178:667-72.

43. Frassanito A, Nicolai A, Nenna R, Cangiano G, Papasso S, Mancino E, et al. Acute viral respiratory tract infections and wheezing at follow-up in children $<3$ years. Eur Respir J. 2015;46:PA1319.

44. Karaman O, Tatli Güneş B, Erbaytaktar Z, Arikan Ayyildiz Z, Babayigit Hocoaglu A, Ölmez D, et al. Recurrence of wheezing episodes in children with respiratory syncytial virus and non- respiratory syncytial virus bronchiolitis. Turkiye Klinikleri J Med Sci. 2011;31:1507-13.

45. Sznajder M, Stheneur C, Albonico V, Dib S, Cau D. Chevallier B; General Pediatrics Group of the French Society of Pediatrics. Respiratory development of 5- to 6- year-old children experiencing a first bronchiolitis episode before age one. Eur Ann Allergy. Clin Immunol. 2005;37:392-6.

46. Hyvärinen M, Piippo-Savolainen E, Korhonen K, Korppi M. Teenage asthma after severe infantile bronchiolitis or pneumonia. Acta Paediatr. 2005;94:1378-83.

47. Valkonen H, Waris M, Ruohola A, Ruuskanen O, Heikkinen T. Recurrent wheezing after respiratory syncytial virus or non-respiratory syncytial virus bronchiolitis in infancy: a 3-year follow-up. Allergy. 2009;64:1359-65.

48. del Rosal T, García-García ML, Calvo C, Muñoz Archidona C, Gozalo F, Pozo Francisco, et al. Asthma and allergy patterns at age 4 to 8 in children with severe bronchiolitis. Eur Respir J. $2013 ; 42: 1152$.

49. Al-Shawwa B, Al-Huniti N, Abu-Hasan M. Respiratory syncytial virus bronchiolitis and risk of subsequent wheezing: a matter of severity. Pediatr Asthma Allergy Immunol. 2006;19:26-30.

50. Kotaniemi-Syrjänen A, Reijonen TM, Korhonen K, Korppi M. Wheezing requiring hospitalization in early childhood: predictive factors for asthma in a six-year follow-up. Pediatr Allergy Immunol. 2002;13:418-25.

51. Kotaniemi-Syrjänen A, Laatikainen A, Waris $M$, Reijonen TM, Vainionpää R, Korppi M. Respiratory syncytial virus infection in children hospitalized for wheezing: virus-specific studies from infancy to preschool years. Acta Paediatr. 2005;94:159-65.

52. Carroll KN, Wu P, Gebretsadik T, Griffin MR, Dupont WD, Mitchel EF, et al. The severity dependent relationship of infant bronchiolitis on the risk and morbidity of early childhood asthma. J Allergy Clin Immunol. 2009;123:1055-61.e1.

53. Eriksson M, Bennet R, Nilsson A. Wheezing following lower respiratory tract infections with respiratory syncytial virus and influenza A in infancy. Pediatr Allergy Immunol. 2000;11:193-7.

54. Fauroux B, Gouyon JB, Roze JC, Guillermet-Fromentin C, Glorieux I, Adamon L, et al. Respiratory morbidity of preterm infants of less than 33 weeks gestation without bronchopulmonary dysplasia: a 12-month follow-up of the CASTOR study cohort. Epidemiol Infect. 2014;142:1362-74.

55. Romero JR, Stewart DL, Buysman EK, Fernandes AW, Jafri HS, Mahadevia PJ. Serious early childhood wheezing after respiratory syncytial virus lower respiratory tract illness in preterm infants. Clin Ther. 2010;32:2422-32.

56. Greenough A, Broughton S. Chronic manifestations of respiratory syncytial virus infection in premature infants. Pediatr Infect Dis J. 2005;24(11 Suppl):S184-7.

57. Pérez Pérez G, Navarro Merino M, Romero Pérez MM, Sáenz Reguera C, Pons Tubío A, Polo Padillo J. 
Respiratory morbidity after hospital discharge in premature infants born at $<$ or $=32$ weeks gestation with bronchopulmonary dysplasia. A Pediatr (Barc). 2004;60:117-24.

58. Vo P, Szabo SM, Gooch KG, Korol EE, Bradt P, Mitchell I, et al. Hospitalization for lower respiratory tract infection increases the risk of childhood respiratory morbidity among children with congenital heart disease. In: 46th annual meeting of the association for European paediatric and congenital cardiology. 2012;PW1-12.

59. Bloemers BL, van Furth AM, Weijerman ME, et al. Down syndrome: a novel risk factor for respiratory syncytial virus bronchiolitis-a prospective birth-cohort study. Pediatrics. 2007;120:e1076-81.

60. Bloemers BL, van Furth AM, Weijerman ME, et al. High incidence of recurrent wheeze in children with Down syndrome with and without previous respiratory syncytial virus lower respiratory tract infection. Pediatr Infect Dis J. 2010;29:39-42.

61. Bont L, Van Aalderen WM, Versteegh J, Brus F, Draaisma JT, Pekelharing-Berghuis M, et al. Airflow limitation during respiratory syncytial virus lower respiratory tract infection predicts recurrent wheezing. Pediatr Infect Dis J. 2001;20:277-82.

62. Greenough A, Alexander J, Boit P, Boorman J, Burgess $\mathrm{S}$, Burke A, et al. School age outcome of hospitalisation with respiratory syncytial virus infection of prematurely born infants. Thorax. 2009;64:490-5.

63. Drysdale SB, Lo J, Prendergast M, Alcazar M, Wilson $\mathrm{T}$, Zuckerman $\mathrm{M}$, et al. Lung function of preterm infants before and after viral infections. Eur J Pediatr. 2014;173:1497-504.

64. Hyvärinen MK, Kotaniemi-Syrjänen A, Reijonen TM, Korhonen K, Korppi MO. Lung function and bronchial hyper-responsiveness 11 years after hospitalization for bronchiolitis. Acta Paediatr. 2007;96:1464-9.

65. Lauhkonen E, Koponen P, Nuolivirta K, Paassilta M, Toikka J, Korppi M. Lung function by impulse oscillometry at age 5-7 years after bronchiolitis at age 0-6 months. Pediatr Pulmonol. 2015;50:389-95.

66. Blanken MO, Rovers MM, Molenaar JM, Winkler-Seinstra PL, Meijer A, Kimpen JL, et al. Respiratory syncytial virus and recurrent wheeze in healthy preterm infants. $\mathrm{N}$ Engl J Med. 2013;368:1791-9.

67. Zomer-Kooijker K, Uiterwaal CS, van der Gugten AC, Wilbrink B, Bont LJ, van der Ent CK. Decreased lung function precedes severe respiratory syncytial virus infection and post-respiratory syncytial virus wheeze in term infants. Eur Respir J. 2014;44:666-74.

68. Cassimos DC, Tsalkidis A, Tripsianis GA, Stogiannidou A, Anthracopoulos M, Ktenidou-Kartali S, et al. Asthma, lung function and sensitization in school children with a history of bronchiolitis. Pediatr Int. 2008;50:51-6.

69. Voraphani N, Stern DA, Wright AL, Guerra S, Morgan WJ, Martinez FD. Risk of current asthma among adult smokers with respiratory syncytial virus illnesses in early life. Am J Respir Crit Care Med. 2014;190:392-8.

70. Juntti H, Kokkonen J, Dunder T, Renko M, Niinimäki A, Uhari M. Association of an early respiratory syncytial virus infection and atopic allergy. Allergy. 2003;58:878-84.

71. Strannegård $\mathrm{O}$, Cello $\mathrm{J}$, Bjarnason $\mathrm{R}$, Sigurbergsson F, Sigurs N. Association between pronounced IgA response in RSV bronchiolitis and development of allergic sensitization. Pediatr Allergy Immunol. 1997;8:1-6.

72. Torgerson DG, Giri T, Druley TE, Zheng J, Huntsman S, Seibold MA, et al. Pooled sequencing of candidate genes implicates rare variants in the development of asthma following severe RSV bronchiolitis in infancy. PLOS ONE. 2015;10:e0142649.

73. Schuurhof A, Janssen R, de Groot H, Hodemaekers HM, de Klerk A, Kimpen JL, Bont L. Local interleukin-10 production during respiratory syncytial virus bronchiolitis is associated with post-bronchiolitis wheeze. Respir Res. 2011;12:121.

74. Bont L, Heijnen CJ, Kavelaars A, van Aalderen WM, Brus F, Draaisma JT, et al. Monocyte IL-10 production during respiratory syncytial virus bronchiolitis is associated with recurrent wheezing in a one-year follow-up study. Am J Respir Crit Care Med. 2000;161:1518-23.

75. Ermers MJ, Hoebee B, Hodemaekers HM, Kimman TG, Kimpen JL, Bont L. IL-13 genetic polymorphism identifies children with late wheezing after respiratory syncytial virus infection. J Allergy Clin Immunol. 2007;119:1086-91.

76. Ermers MJ, Janssen R, Onland-Moret NC, Hodemaekers HM, Rovers MM, Houben ML, et al. IL10 family member genes IL19 and IL20 are associated with recurrent wheeze after respiratory syncytial virusbronchiolitis. Pediatr Res. 2011;70:518-23.

77. Goetghebuer T, Isles $\mathrm{K}$, Moore C, Thomson A, Kwiatkowski D, Hull J. Genetic predisposition to wheeze following respiratory syncytial virus bronchiolitis. Clin Exp Allergy. 2004;34:801-3. 
78. Thomsen SF, van der Sluis S, Stensballe LG, Posthuma D, Skytthe A, Kyvik KO, et al. Exploring the association between severe respiratory syncytial virus infection and asthma: a registry-based twin study. Am J Respir Crit Care Med. 2009;79:1091-7.

79. Stensballe LG, Simonsen JB, Thomsen SF, Hellesøe Larsen AM, Hovmand Lysdal S, Aaby P, et al. The causal direction in the association between respiratory syncytial virus hospitalization and asthma. J Allergy Clin Immunol. 2009;123:131-7.

80. Castro M, Schweiger T, Yin-Declue H, Ramkumar TP, Christie C, Zheng J, et al. Cytokine response after severe respiratory syncytial virus bronchiolitis in early life. J Allergy Clin Immunol. 2008;122:726-733.e3.

81. Silver E, Yin-DeClue H, Schechtman KB, Grayson $\mathrm{MH}$, Bacharier LB, Castro M. Lower levels of plasmacytoid dendritic cells in peripheral blood are associated with a diagnosis of asthma $6 \mathrm{yr}$ after severe respiratory syncytial virus bronchiolitis. Pediatr Allergy Immunol. 2009;20:471-6.

82. Kitcharoensakkul $M$, Bacharier LB, Yin-Declue $H$, Schweiger T, Goss CW, Boomer JS, et al. Increased nasal plasmacytoid dendritic cells are associated with recurrent wheezing following severe RSV bronchiolitis. J Allergy Clin Immunol. 2016;137:L9.1.

83. Nenna R, Ferrara M, Nicolai A, Pierangeli A, Scagnolari C, Papoff P, et al. Viral load in infants hospitalized for respiratory syncytial virus bronchiolitis correlates with recurrent wheezing at thirty-six-month follow-up. Pediatr Infect Dis J. 2015;34:1131-2.

84. Calvo Rey C, García García M, Albañil Ballesteros M. Bronchiolitis and persistent wheezing. Is eosinophilia a risk factor? An Esp Pediatr. 2001;55:511-6.
85. Ehlenfield DR, Cameron K, Welliver RC. Eosinophilia at the time of respiratory syncytial virus bronchiolitis predicts childhood reactive airway disease. Pediatrics. 2000;105:79-83.

86. Pifferi M, Ragazzo V, Caramella D, Baldini G. Eosinophil cationic protein in infants with respiratory syncytial virus bronchiolitis: predictive value for subsequent development of persistent wheezing. Pediatr Pulmonol. 2001;31:419-24.

87. Kristjánsson S, Wennergren D, Eriksson B, Thórarinsdóttir $\mathrm{H}$, Wennergren G. U-EPX levels and wheezing in infants and young children with and without RSV bronchiolitis. Respir Med. 2006;100:878-83.

88. Stensballe LG, Ravn H, Kristensen K, Agerskov K, Meakins T, Aaby P, Simões EA. Respiratory syncytial virus neutralizing antibodies in cord blood, respiratory syncytial virus hospitalization, and recurrent wheeze. J Allergy Clin Immunol. 2009;123:398-403.

89. Rolfsjord LB, Skjerven HO, Bakkeheim E, Carlsen $\mathrm{KH}$, Hunderi JO, Kvenshagen BK, et al. Children hospitalised with bronchiolitis in the first year of life have a lower quality of life nine months later. Acta Paediatr. 2015;104:53-8.

90. Rolfsjord LB, Skjerven HO, Carlsen KH, Mowinckel $\mathrm{P}$, Bains KE, Bakkeheim E, et al. The severity of acute bronchiolitis in infants was associated with quality of life nine months later. Acta Paediatr. 2016;105:834-41.

91. Greenough A, Alexander J, Burgess S, Bytham J, Chetcuti PA, Hagan J, et al. Health care utilisation of prematurely born, preschool children related to hospitalisation for RSV infection. Arch Dis Child. 2004;89:673-8. 